\title{
DIREITO E AS NOVAS UTOPIAS
}

JoÃo LUIZ Stefaniak

Graduado em Direito, Mestre em Ciências Sociais Aplicadas e Doutorando em Geografia pela Universidade Estadual de Ponta Grossa.

Silvana de Souza Netto Mandalozzo

Graduada em Direito pela Universidade Estadual de Ponta Grossa, Mestre e Doutora em Direito pela Universidade Federal do Paraná.

\section{Resumo}

Este artigo propóe uma breve incursão no território das Novas Utopias que emergem das grandes mobilizaçôes sociais que marcam o início da segunda década deste século. Diferentemente do utopismo tradicional (da forma espacial) ou do utopismo dos processos temporais as Novas Utopias se aproximam do utopismo dialético histórico-espacial proposto por David Harvey. As Novas Utopias são projetadas simultaneamente às práticas que se denvolvem em um território específico, que são as ruas e praças das grandes cidades. Neste contexto o artigo busca evidenciar a imbricação do pensamento utópio contemporâneo com o Direito, na perspectiva de romper com o seu papel ideológico de regulamentação da opressão.

\section{Palavras-chave}

Utopia; Ideologia e direito.

\section{Resumen}

En este artículo se propone una breve incursión en la Nuevas Utopías que emerge de las principales movilizaciones sociales que marcan el comienzo de la segunda década de este siglo. Así diferente la utopía tradicional (la forma espacial) la utopía de los procesos temporales las Nuevas Utopías acercan al utopía dialéctica, histórica y espacial propuesto por David Harvey. Las nuevas utopías están diseñadas tanto para prácticas que sucede en un territorio específico, que son las calles y plazas de las grandes ciudades. En este contexto, el artículo busca demostrar el entrelazamiento del pensamiento utópico contemporáneo con el Derecho, con el fin de romper su función ideológica de la regulación de la opresión. 


\section{Palabras clave}

Utopía; la ideología y el derecho.

"Utopias são ideias inspiradoras das classes em rebelião e ascensão, em oposição às ideologias que racionalizam e estratificam o pensamento das classes dominantes" (Karl Mannheim)

\section{Introdução}

Comeceça este artigo citando a máxima de Oscar Wilde: "um mapa do mundo que não aparece o país Utopia não merece ser guardado". Ela expressa a busca permanente pela criação de uma sociedade ideal que move um grupo expressivo de pessoas. Para o Direito, nas palavras de João Batista Herkennhoff, "um papel decisivo está reservado ao pensamento utópico" (HERKENHOFF, 2004, p. 17). Este artigo se debruça sobre este papel que a Utopia cumpre em relação ao Direito, tentando situar a atualidade do resgate do pensamento utópico e sua imbricação direta com as Ciências Jurídicas.

No final do século passado, desfeita a quimera socialista com a queda dos muros reais e ideológicos que por tráz escondiam uma sociedade longe de ser perfeita (longe da utopia cronstruída no final do século anterior e nos primórdios do século XX), muitos vociferaram a capitulação de todas as Utopias e o próprio fim da História pelo triunfo do pensamento único expresso na realidade imposta pelo sistema dominante. No entanto, esta presunçosa proclamação dos arautos defensores do capitalismo teve um curto período de duração e, curvados pela crise estrutural do sistema que se confirmou no início deste novo século, viram ressurgir com força um novo movimento de construção de Novas Utopias.

Este artigo propóe uma breve excursão no território construído por estas Novas Utopias. Nem de longe se pretende aprofundar e muito menos esgotar a análise do conteúdo delas. Como um viajante em curto passeio vai destacar as impressóes mais significativas e os fenômenos que afloram neste processo de resgate do pensamento utópico. Vai descrever as utopias tradicionais que ainda inspiram as Novas Utopias para em seguida comentar a crítica ao pensamento utópico, que teve na figura de Karl Marx seu expoente, e depois explicitar a ideologia como oposição a utopia. No ambito dos estudos geográficos merece o destaque a contribuição de David Harvey e sua proposta de Utopia Dialética, que será resumidamente analisada. E finalmente, o artigo irá discorrer sobre os territórios das Novas Utopias constituídos a partir das grandes mobilizaçóes sociais que marcaram o início da segunda década deste século dando enfaze a topus principal de sua formulação e materialização: a rua, e sua imbricação com o Direito, em especial no contexto proposto por João Baptista Herkenhoff. 


\section{Utopias Clássicas}

O termo "utopia” em grego significa "não lugar" ou "em lugar nenhum" e foi usado por Thomas More (Morus em latim) para designar a ilha imaginária descrita em sua obra homônima, cujo título original é "De Optimno Publicae Statuo Duque Nova Insula Utopia”, escrita em 1516.

Morus na sua Utopia descreve uma sociedade comunista imaginária situada numa ilha governada por uma assembléia eleita que tem por principal atribuição evitar os desiquilíbrios sociais e garantir a igualdade aos seus cidadãos. A inspiração em Platão, autor da célebre "República" é evidente na obra de Morus, que também influenciou outro pensador utópico da Renascença, o italiano Tommasso Campanella, que em 1602 escreveu a sua mais importante obra intitulda "A Cidade do Sol".

Esta tríade de autores representam os expoentes do pensamento utópico clássico que tem em comum, além do idealismo, a crítica contundente ao sistema econômico e social vigente a época dos escritos de suas respectivas utopias.

Arístocles, de cognome Platão (428 a.C a 348 a.C), pensador ateniense, teve como mestre Sócrates ( 470 a.C a 399 a.C) que foi injustamente condenado a morte ao contrariar os interesses da minoria que detinha o poder na democracia ateniense. Este episódio levou Platão a total desilusão com a política e a justiça de Atenas, o que vai municiar a crítica social expressa no resgate do mito de Atlântida em "Crítias", quanto à ideliazaçáo da cidade (polis) ideal descrita na "República", onde prevalece uma divisão racional do trabalho e a governança de reis-filósofos eleitos dentre a classe dos guardióes, incumbidos de zelar pelo cumprimento das leis. Reformador radical, Platão idealiza uma sociedade onde a família deixa de existir, onde as mulheres são comuns a todos os guardióes e as crianças seriam educadas pela cidade.

Também Morus vai descrever através de sua ilha utópica uma sociedade igualitária e harmoniosa em contraste com a situação vivida na Inglaterra de sua época. Para seu intento, de sua Utopia "ele excluiu as forças potenciamente disruptivas do dinheiro, da propriedade privado, do trabalhado assalariado, da exploração", bem como a "troca interna (mas não externa) de mercadorias, a acumulação do capital e o processo do mercado (ainda que não o mercado)" (HARVEY, 2009, p. 211)

Igualmente Campanella, provido de uma mente crítica e inquieta, foi por várias preso como herético e sodomista, sendo que em Calábria, sua cidade natal, chefiou uma rebelião, inconformado com a miséria e a injustiça imposta pelo jugo espanhol, permanecendo preso por vinte e sete anos, período em que escreveu a utopia "A Cidade do Sol", onde idealizou uma sociedade naturalista e teocrática onde seriam abolidas a propriedade privada e a família, dando lugar a uma comunidade de bens e de mulheres. 
Além da crítica social implicita na construção destas sociedades utópicas imaginárias, outra característica do utopismo clássico, que se denota da leitura da tríade análisada é, como afirma David Harvey, que todas essas formas de utopia podem ser caracterizadas como 'utopias da forma espacial', pois a temporalidade dos processos sociais" é suprimida, "ao passo que a estabilidade social é garantida por uma forma espacial fixa" (HARVEY, 2009, p. 13). Mas do que uma "utopia da forma espacial" o pensador francês Henri Lefebvre encontra na obra dos utopistas clássicos uma "espécie de comunismo urbano que não seria nem camponês, nem ascético, nem artesanal”, para afirmar a seguir que o "comunismo utópico tem fontes urbanas tanto quanto agrárias”. (LEFEBVRE, 2008, p. 98).

De fato, vamos encontrar a referência ao urbano já no próprio nome da obra de Campanella, bem como é intensa a referência a "polis" tanto na "República" como em "Crítias" de Platão. E mesmo na Utopia de Morus detacasse a referência "as cidades da ilha, com especial menção de Amaurota”, (MORE, 2005, p. 56) capital daquela república fictícia.

E finalmente, uma terceira característica comum entre as obras destacadas é a busca dos autores do Eterno Retorno a um passado virtuoso, que o desenvolvimento econômico e social a eles contemporâneo corrompeu. Portanto, neste sentido específico a utopia é a contrapartida para o futuro do mito de uma idade áurea, que teria existido em um remoto passado.

Estes traços marcantes do utopismo que chamamos de clássico, que em diferentes intensidades vão influenciar o pensamento útópico posterior, também vai refletir nas tentativas de materializaçóes das utopias de forma espacial, em especial no que se refer as experiências dos chamados socialistas utópicos, com destaque para Robert Owen e Charles Fourier.

\section{Crítica das Concepções Utopicas}

Bastante conhecida é a crítica contundente de Marx e Engels aos chamados socialistas utópicos que lhe eram contemporâneos, apesar de enaltecer os escritos dos fundadores destas correntes, destacando Saint-Simon, Fourier e Owen, que "aparecem no primeiro período da luta entre o proletariado e a burguesia" e que representam "a primeira aspiração... de uma transformação geral da sociedade". A oposição marxiana decorre da "descrição fantástica da sociedade futura" (MARX; ENGELS, 1986, p. 118) e pela aversão a ação revolucionária e ao protagonismo da classe operária das correntes utopistas do socialismo. No entanto, a obra de Marx e Engels não se restringe a análise da sociedade capitalista, pois resulta na formulação da práxis emancipadora do proletariado, que liberto das amarras da dominaçáo burguesa, iria construir uma nova sociedade. 
Apesar de fundamentada em um arsenal metodológico poderoso, que permitiu formular a mais consistente crítica ao capitalismo, a nova sociedade prognosticada por Marx e Engels guarda similitude com a Utopia de Morus, pois contemporaneamente aos jovens escritores do Manifesto Comunista, o socialismo era um Não-Lugar, pois não existia no mundo real. Uma das diferenças desta "utopia marxiana" com os seus antecessores é justamente a existência de um embasamento teórico, capaz de revelar as contradiçóes inerentes à sociedade capitalista, que aliado à práxis emancipadora do proletariado, classe protagonista da revolução social, permitiria construir sob novas bases estruturais, a utopia comunista almejada.

Neste contexto, pode-se afirmar como faz David Harvey que para Marx "o futuro tem que ser construído não segundo algum molde utópico fantástico, mas por meio de transformações tangíveis das matérias-primas que temos à disposição em nossa atual condição" (HARVEY, 2009, p. 251). Como enfatiza Henri Lefebvre, Marx recusava a procura de "prever ou imaginar o futuro... pois concebia a 'via' e não o 'modelo"” (LEFEBVRE, 2008, p. 102).

Então, pode-se concluir a partir da reflexão acima explicitada que, se entender possível falar em "utopia marxiana", ela se aproxima do conceito de "utopismo do processo social" definido por David Harvey. O geográfico inglês faz a distinção entre "o utopismo do processo temporal ao lado utopismo da forma espacial" (HARVEY, 2009, p. 228) e que seja considerado também utópicos os esquemas imaginários dos processos sociais. $\mathrm{O}$ pensamento de Marx pode ser enquadrado nesta categoria de processo social temporal utópico onde através da luta de classes "as classes-em-si, ao se transformar em classes -para-si, movem a história na direção do Estado aprimorado da sociedade comunista pós-revolucionária sem classes - em que o próprio Estado acaba por desmanchar-se no ar." (HARVEY, 2009, p. 229).

Apesar de Marx ser considerado o grande adversário das concepçôes utópicas clássicas (de forma espacial) ao derrotar os defensores do socialismo utópico e propor o socialismo científico, pode-se afirmar que sua proposta de utopia do processo social foi exitosa. O pensamento de Marx constituiu a base teórica das grandes revoluçóes socialistas, que a partir da Revolução Soviética replicaram em grande parte do globo. No entanto, a vitória da "utopia marxiana" foi efêmera, uma vez que o chamado "socialismo real" se revelou em grande parte uma distopia (ou antitopia), ou seja, uma sociedade autoritária e opressora, que renegou na prática, a quimera de igualdade e justiça social preconizada pelo movimento comunista.

Ao longo do século passado, enquanto perdurou a divisão do mundo entre países capitalistas e comunistas o conceito de utopia, que já se encontrava totalmente desacreditado ante a falência dos projetos utópicos posto em prática por Fourier, Owen e Étienne 
Cabet, entre outras experiências malogradas, foi totalmente refutada, pois os projetos de organização social concebidos passam a ter como paradigma experiências concretas: o socialismo real e o Estado de Bem Estar Social instituído principalmente na Europa pelos governos liderados pelos partidos socialistas e trabalhistas de matiz reformista.

O pensamento utópico somente vai ressurgir no final dos anos sessenta do século passado a partir dos movimentos liderados pelos estudantes franceses inspirados nas teorias de Herbert Marcuse e ganha mais força com a derrocada das ideologias socialistas e neoliberais, que vão ocorrer no final dos anos oitenta e no final da primeira década do Século XXI. Surgem então as Novas Utopias.

\section{Ideologia, Miragem e Utopia}

Abrir parênteses é necessário para o bom desenvolvimento deste artigo. Na realidade, o contexto que se propóe expor o florescimento contemporâneo das Novas Utopias se dá ao mesmo tempo em que ocorre a "crise das ideologias". Na realidade este artigo é o desdobramento de uma reflexão do autor que envolve estes dois conceitos, que são contrapostos: ideologia e utopia.

A priori a frase de Karl Mannheim emprestada de sua obra "Ideologia e Utopia" publicada pela primeira vez em 1929 e que serve de epiteto deste artigo, resolve de forma sintética esta contraposição. Porém, é necessário para clarificar esta oposição entre os conceitos explicitar o que se entende aqui por ideologia.

Etimologicamente, ideologia significa o estudo das ideias. Mas como demonstraram Marx e Engels as ideias são produtos da realidade material e somente podem ser produzidas a partir das relaçóes materiais da sociedade. A ideia é a linguagem (as representaçôes) da vida real. Mas a ideologia não é composta apenas por ideias abstratas que habitam o "pensamento" dos indivíduos. Evidente que para ser operara a ideologia precisa adquirir certa materialidade que extrapola o mundo do "pensamento", pois ela se traduz em de signos, símbolos e marcas, que não apenas representam o real, mas precisam substituir o real uma vez que a realidade é o que a ideologia pretende ocultar. A ideologia é "quase material".

A expressão "quase material" aqui utilizada é para contrapor a tese formulada por Louis Althusser que a "ideologia tem uma existência material" (ALTHUSSER, 1970, p. 83), pelo simples fato de que se admitir que ideologia seja matéria, com ela se confundiria que seria impossível distinguir o real e as representaçóes do real do que é ideológico, impedindo desta forma que as contradiçóes do sistema capitalista (e que a ideologia tem justamente o papel de ocultar) deixem de ser "percebidas", condenando-se assim, a humanidade a completa imobilidade histórica. 
O espaço, em especial o espaço urbano, é produzido enquanto ideologia. Ele é "concebido" pelos urbanistas e outros ideólogos a serviço das classes dominantes e torna-se operativo através das práticas espaciais. O êxito da "ideologia espacial” é proporcional a sua capacidade de fazer com que o "vivido" pelos habitantes das cidades se confunda com o "concebido" pelos ideólogos. A ideologia não constitui a integralidade da prática espacial, mas ela é operacionalizada por meio de práticas que são "[re]produzidas" no cotidiano dos citadinos de forma que aparente como a única realidade possível, tornando as contradiçóes da sociedade urbana naturais e irremediáveis. Desta forma a ideologia transforma o espaço urbano em uma miragem, com será explicitado adiante.

Porém a cidade, como afirma Marx e Engels na "Ideologia alemã", surge historicamente da primordial divisão social do trabalho, ou seja, a divisão da cidade e do campo. Como o desenvolvimento dos modos de produção, a cidade, que se define como espaço de concentraçáo das diversas determinaçóes da realidade social em detrimento ao campo, o espaço da dispersão destas mesmas determinações, também passa a ser cada vez mais o espaço da concentração das práticas ideológicas. Assim os ideólogos são impelidos a formularem (conceberem) "práticas ideológicas" mais sofisticadas, em virtude da "complexificação" da sociedade, pois na sociedade urbana a divisão social do trabalho e as contradições inerentes decorrente dos conflitos de classe se tornam cada vez mais complexos.

Diante de tal sofisticação da ideologia seria no mínimo ingênua a aposta em conceber uma "ideologia revolucionária" do espaço. Por isto se faz necessário retomar o conceito marxiano de ideologia e a tradição de crítica ao capitalismo iniciada por Marx. Diante da magnitude da ideologia imposta pela classe dominante a única aposta possível é que, através do desvelar da exploração e dominação dos detentores do capital sobre as demais classes sociais, se possa construir coletivamente uma proposta de nova cidade e de sociedade, que se reproduza no imaginário social, em uma representação específica: a utopia.

Quanto o termo miragem, que exprime esta "materialidade" específica das representações e das ideologias na produção social do espaço, vale retomar a explanação apresentada pelo autor deste artigo em sua dissertação de mestrado, intitulada "Entre a miragem e a utopia: a efetividade do direito humano e fundamental à moradia na cidade capitalista":

A miragem é uma imagem causada pelo desvio da luz refletida por um determinado objeto, ou seja, é um fenômeno físico, real e não apenas uma ilusão de óptica. Portanto, a alegoria do viajante perdido no deserto, que alucinado enxerga um oásis inexistente no horizonte, é parcialmente falso. De fato, este viajante vê a miragem, que é um fenômeno óptico real, mas as suas condiçóes subjetivas o induzem a imaginar a existência do oásis no lugar onde ocorre o desvio da luz refletida.

A cidade é um fenômeno concreto. Mas é vista pela maioria como uma miragem, que não é provocada por um fenômeno óptico, mas por uma 
ideologia, através de mecanismos (aparelhos) utilizados pelo Estado capitalista, na sua precípua missão de perpetuar a dominação de classe. A miragem na cidade capitalista também é um fenômeno real e objetivo, que se traduz na concretude destes instrumentos ideológicos, mas que conta com o fator subjetivo para alcançar o efeito almejado: a ausência da autoconsciência da realidade por parte da maioria dos citadinos. $\mathrm{O}$ morador confinado em um determinado espaço da urbe, pode até sentirse vítima desta segregaçáo, mas nem sempre compreende as razóes que determinam esta realidade.

O materialismo dialético é o método que permite revelar a cidade capitalista e fazer emergir as contradiçóes que lhe sáo inerentes, uma vez que possibilita enxergar para além desta miragem ideologicamente construída. E ao se alcançar a realidade urbana são expostos os mecanismos estruturais da dominação burguesa. Este domínio de uma classe sobre outra guarda ainda uma dimensão social, cultural e histórica que está imbricada com a primordial divisão social do trabalho, que originou a cidade como sede da classe dominante que expropriou o excedente produzido do campo. Porém, o desenvolvimento histórico da cidade, apesar das miragens criadas pelas classes dominantes, sempre foi marcado pelo antagonismo de classes.

A hodierna cidade capitalista foi precedida por formas de organização urbana que refletiam diferentes modos de produção. No ocidente a cidade antiga foi palco das rebelióes de escravos e plebeus e os muros da cidadela medieval testemunharam as rebelióes camponesas contra o regime feudal. Além da revolta contra a dominação a que eram submetidos, outro sentimento mobilizavam os explorados, especialmente nos momentos que estes conflitos atingiram seu ápice revolucionário: a aspiração de construir uma nova cidade, livre da opressão e das injustiças. (STEFANIAK, 2011, p. 203/204).

\section{A Utopia Dialética de David Harvey}

A partir do processo de retomada do pensamento utópico que ocorreu no final do século passado e continua neste período, muitos teóricos tem se destacado na formulação de conceitos e projetos utópicos. Merece destaque como precursor deste movimento de resgate da utopia Karl Mannheim, sendo que vários autores se debruçaram sobre o tema contemporaneamente.

Com certeza uma das significativas contribuições sobre o estudo das concepções utópicas é aquela apresentada por David Harvey em seu livro "Espaços de Esperança", publicado em 2000, onde ao longo capítulo "O Momento Utópico" discorre uma consistente crítica tanto dos utopismos tradicionais (de forma espacial) como aqueles que 
se caracterizam como utopias do processo social, para então apresentar o conceito de Utopismo Dialético.

O Utopismo Dialético parte da premissa de que desde Einstein "não é possível separar de modo coerente o tempo e o espaço" (HARVEY, 2009, p. 239) o que implica na concepção de um utopismo explicitamente espaço-temporal, que busca a superação das debilidades encontradas tanto na utopia tradicional da forma espacial como a do processo social.

Harvey contextualiza o atual debate acerca do resgate utopista a partir do "colapso de formas utópicas específicas", onde "o comunismo se acha em profundo descrédito como projeto utópico, e em nossos dias o liberalismo vem sendo visto cada vez mais como um projeto que não pode dar certo." (HARVEY, 2009, p. 256). E preconiza que "há um momento e um lugar no incessante labor humano de mudança do mundo em que as visóes alternativas, por mais fantásticas que sejam, oferecem a base para moldar poderosas forças políticas de mudança. Creio que nos encontramos precisamente num desses momentos" (HARVEY, 2009, p. 257).

Importante frisar que Harvey não labora com a contraposição da ideologia e a utopia e classifica como utopia dos processos o que denomina utopia do mercado que "se fundava nas atividades racionais do 'homem econômico' num contexto de mercados perfeitos." (HARVEY, 2009, p. 230).

Realizada a crítica as formas utópicas específicas passa então Harvey a desenvolver sua proposta de Utopia Dialética que consiste em construir um utopismo espaço-temporal "que tenha raízes fincadas em nossas possibilidades presentes ao mesmo tempo que aponta trajetórias diferentes para os desenvolvimentos geográficos desiguais humanos" (HARVEY, 2009, p. 258). Para tanto, o geográfico inglês vai fazer uso da alegoria que compara o trabalho dos arquitetos e abelhas, sendo que a principal distinção entre ambos é que "o arquiteto concebe na mente sua construção antes de transformá-la em realidade" e "ao final do processo obtém-se um resultado que já existia na imaginação do trabalhador desde o começo.” (MARX, apud HARVEY, 2009, p. 263).

E contrariando a tradição marxista que a renega Harvey vai enfatizar a existência de uma natureza humana através da concepção de "ser em nossa espécie" o que implica em "nossas capacidades de transformar o mundo por meio do trabalho e, por meio disso, transformar a nós mesmos" e se soma a capacidade "de falar de como por em prática nossa imaginação, ainda que sujeita a restriçóes, na busca de realização de tal projeto" sendo que a partir da caracterização desta natureza do homem de "seres sensoriais em relação com o mundo que nos cerca" (HARVEY, 2009, p. 271/272) leva a formulação de um repertório básico de opçóes estratégicas para a ação humana que consiste na: competição e luta pela existência; a adaptação e diversificação em nichos ambientais; a colaboração e a ajuda 
mútua; as transformaçóes ambientais; as organizaçóes espaciais; e as ordenaçóes temporais. Os seres humanos então se distinguem das outras espécies animais pela capacidade de chegar "as formas ricas e flexíveis de combinar os diferentes elementos" deste repertório básico "em complexos sistemas sociais" (HARVEY, 2009, p. 275).

A concepção de uma utopia dialética em Harvey vai enfatizar o que ele chama de responsabilidade perante a natureza e perante a natureza humana, o que corresponde à incorporação de um determinado discurso ecológico que contemple o equilíbrio entre a defesa da natureza e a defesa dos direitos sociais. Harvey afirma que:

Isto requer como reação que se organize um projeto de classe igualmente forte de prevenção e redução de risco, de recuperação e controle de recursos, em que a classe trabalhadora, os destituídos e os marginalizados assumam um papel de liderança. No momento em que eles estiverem desempenhando este papel, vai ser possível trazer à baila toda a questão de construir um modo alternativo de produção, de troca e de consumo que não apenas reduza os riscos, como também seja ambiental e socialmente justo e sensível. (HARVEY, 2009, p. 292)

Assim, após a explanar a relação entre o utopismo espaço-temporal e as qualidades ecológicas implicitamente necessárias para a compreensão do projeto utópico proposto, David Harvey, passa a discorrer sobre as potencialidades e capacidades, bem como das açóes concretas deste "arquiteto rebelde", figura que traveste todos aqueles que se empenham em transformar o mundo.

Segundo Harvey este arquiteto rebelde é uma pessoa corporificada que ocupa um espaço exclusivo por uma dado período de tempo e "dotado de certas capacidades e habilidades passíveis de ser usadas para transformar o mundo" (HARVEY, 2009, p. 307). Apesar de reconhecer a importância da "pessoa política", Harvey salienta que a construção da utopia dialética não pode prescindir "de algum tipo de coletivização do impulso e desejo de mudança", sendo que a comunidade surgida neste processo "deveria ser vista como uma delicada relação entre processo fluidos e regras relativamente permanentes de pertinência e associação”. (HARVEY, 2009, p. 312-314).

Outra contradição que é necessária superar para a compreensão do modelo utópico proposto por Harvey é aquela que envolve o particularismo militante (onde todos os movimentos políticos de base ampla têm por origem lutas específicas em lugares momentos particulares) e a tendência de busca dos universais que se constroem através das traduçóes de aspiraçóes políticas variáveis e heterogêneas. Deste processo resulta a constituição de princípios universais que balizariam a ação política transformadora.

David Harvey propóe uma lista de direitos universais que julga necessários percorrer para a construção do projeto utópico, são eles: direito a oportunidade de vida; direito 
à associação política e a um "bom" governo; direitos dos trabalhadores envolvidos diretamente com o processo produtivo; direito à inviolabilidade e à integridade do corpo humano; direito de imunidade para o exercício da desestabilização do que existe; direito a um ambiente de vida decente e saudável; direito ao controle coletivo de recursos de propriedade comum a todas as pessoas; direitos daqueles que ainda vão nascer; direito à produção do espaço; direito à diferença, incluindo o direito ao desenvolvimento geográfico desigual; e, finalmente os direitos como seres de espécies, que se "traduz no direito de explorar a possibilidade de diferentes combinaçôes dos itens de nosso repertório evolutivo" (HARVEY, 2009, p. 330). E complementa que:

$\mathrm{O}$ arquiteto rebelde tem que de ser um defensor desses direitos. Ao mesmo tempo, ela ou ele têm de reconhecer com clareza que sua formulação advém da vida social e que essa formulação permanece fútil e privada de sentido exceto se concretizada de modo tangível em instituiçóes mediadoras, processos de transformação de comunidades e nas maneiras como o pessoal é entendido e se faz ação na forma do político. (HARVEY, 2009, p. 331)

Finalmente o autor deste projeto utópico em análise vai situá-lo em uma perspectiva de uma revolução histórico-geográfica permanente que se desenvolve em uma pluralidade de práticas que exigem o diálogo aberto e interativo para potencializar o seu poder de transformação, sendo que só assim "será possível evitar que o impulso rumo ao utopismo dialético se dissolva no utopismo árido, e em última análise destrutivo, seja da forma espacial fechada ou dos processos temporais de perpétua destruição criadora" (HARVEY, 2009, p. 332)

Sem dúvida a Utopia Dialética proposta por Harvey se traduz em um arcabouço teórico para que se possa, em tempos de florescimento da aspiração utópica que se atravessa entender o processo de diálogo e interação entre as práticas transformadoras que atualmente se revelam nas grandes manifestaçóes que ocorrem nas metrópoles de vários países. Em todos eles, o território que se reproduz os processos utópicos é o mesmo: a rua.

\section{Território das Novas Utopias e sua Imbricação com o Direito}

Território neste artigo tem correspondência precisa com a definição proposta por Marcelo Lopes de Souza, ou seja, "é, fundamentalmente, um espaço definido e delimitado por e a partir de relações de poder" (SOUZA, 2006, p. 331). Para definir o que é poder o autor utiliza a ideia de poder enquanto potência de Hannah Arendt, que exemplifica: "a revolta popular contra governantes materialmente fortes pode gerar um poder praticamente irresistível, mesmo quando se renuncia a violência face às forças materiais vastamente superiores”. (ARENDT, 2003, p. 212) Então, para Hannah Arendt o poder 
não é sinônimo de força, mas sim a capacidade transformadora que pode ser expressa na revolta (mesmo que pacífica) dos povos contra governos (mesmo aqueles que se impóe pela força).

Este "poder praticamente irresistível" das revoltas sociais somente se potencializa quando fundado em um projeto utópico igualmente irresistível. E também quando o embate ocorre em determinado território apropriado para o exercício deste poder-potência popular. Qual seria então o território que melhor desenvolve as lutas emancipatórias propícias para o desenlace dos projetos utópicos neste determinado momento histórico? A resposta que se revela sem dúvida é que são as ruas dos grandes centros urbanos.

São exemplo deste fenômeno as grandes manifestaçôes que sacudiram o cenário político e social mundial a partir de 2011, como a "Primavera Árabe", "Occupy Wall Street", nos Estados Unidos, e "Los Indignados" ou "Movimento 15M" na Espanha, além da "Revolta da Praça Taskin", na Turquia, e no caso brasileiro as "Jornadas de Junho", ocorridas em 2013, onde as ruas e as praças dos grandes centros urbanos constituem não apenas o cenário onde se desenvolve os embates, mas também o território em que se projetam as Novas Utopias.

O estopim das "Jornadas de Junho" foi a manifestação convocada pelo Movimento Passe Livre (MPL), no dia 7 de junho de 2013, contra o aumento da tarifa dos ônibus do transporte público em São Paulo, que contou com a participação de pouco mais de duas mil pessoas, a grande maioria estudantes, e que ganhou destaque nas manchetes dos órgãos da grande imprensa, pela violência com que a polícia militar paulista reprimiu os manifestantes. Já o auge do movimento foi o dia 20 de junho, que mobilizou quase dois milhóes de manifestantes em mais de quatrocentas cidades brasileiras. Esta explosão do movimento contestatório pode ser explicada em parte pela chamada "propagação viral" através das redes sociais da Internet e que foram utilizadas em outros protestos.

As "Jornadas de Junho", em muitos aspectos, não se enquadram aos esquemas teóricos e práticas vinculadas ao utopismo socialista ou comunista, que como se afirmou anteriormente, encontra-se em franca decadência. Mesmo os atores tradicionais que encabeçaram os movimentos de massa do século passado, os partidos de esquerda e os sindicatos, têm uma participação restrita nestes novos movimentos. Surgem novos ativistas, que refutam as velhas ideologias que outrora impulsionaram as lutas emancipatórias.

A formulação dos projetos utópicos se dá a partir da reflexão a partir das práticas concretas que igualmente se desenvolvem coletivamente nas ruas e demais espaços comuns, principalmente nas redes sociais informatizadas. Estes movimentos se organizam como espelho que reflete a sociedade utópica almejada: o poder potência é exercido comunitariamente e as decisóes são tomadas de forma horizontal, sem a constituiçáo de uma vanguarda dirigente que orienta as açóes políticas. A contestação ao sistema econômico e 
político dominante é explicitada através de palavras de ordens que revelam uma pluralidade de demandas e reivindicaçóes.

Constituídos majoritariamente por jovens todos os grandes movimentos de massa que marcaram o início da segunda década deste novo século marcam o deslocamento espacial das lutas sociais que no século passado tinham como palco o "chão das fábricas". A luta pelos direitos trabalhistas dá lugar a centralidade das lutas pela efetivação do direito à cidade, definido por Henri Lefebvre como a "forma superior dos direitos: direito à liberdade, à individualização na socialização, ao habitat e ao habitar", bem como o "direito à obra (à atividade participante) e o direito à apropriação (bem distinto do direito à propriedade privada)" (LEFEBVRE, 2008, p. 134).

Descrita o espaço territorial onde se desenvolve as lutas emancipatórias que distinguem as Novas Utopias resta discorrer sobre o papel do Direito na formulaçáo e constituição do pensamento utópico contemporâneo.

A teoria marxista de maneira geral denuncia o caráter ideológico (no seu sentido marxiano) do direito e as algumas correntes tendem a desqualificar totalmente o papel do direito, restringindo-o ao seu papel de legitimação do processo de exploraçáo e dominação de classe. No entanto, como já salientava Eugeny Pasukanis no início do século passado a "natureza ideológica de um conceito não suprime a realidade e a materialidade das relaçóes das quais ele é expressão" (PASUKANIS, 1989, p. 56). Para Pasukanis o direito é reflexo de relações sociais concretas, operadas por sujeitos juridicamente assim definidos, e mesmo que servindo de miragem (na forma proposta pelo autor anteriormente) pela classe dominante, não é apenas uma abstração construída com este fim, pois o direito não é apenas emanaçáo da norma, pois “ou é deduzida diretamente de relaçóes preexistentes, ou, entáo, representa, quando promulgada como lei estatal, um sintoma do que nos permite prever, como uma certa verossimilhança, o futuro nascimento de relaçóes correspondentes" (PASUKANIS, 1989, P. 57).

Porém, apesar do Direito constituir um fenômeno social concreto é forçoso reconhecer o seu papel normatizado das relaçóes sociais que sustentam o sistema sócio econômico dominante. Neste sentido é que emerge o papel do pensamento utópico, que ao mesmo tempo cumpre a função de favorecer a crítica da realidade e constituir uma forma de ação contra as injustiças. Como afirma atesta João Baptista Herkenhoff:

É a utopia que dá luzes para ver e julgar o Direito vigente na sociedade em que vivemos e para estigmatiza-lo como um Direito que apenas desempenha o papel de regulamentar a opressão; um Direito da desigualdade; um Direito injusto, porque, no processo da produção, privilegia o capital; um Direito que, consagrando essa distorção básica, faz com que dela decorra uma rede de distorçôes que maculam todos os institutos jurídicos (HERKENHOFF, 2004, p. 17). 
Neste contexto a imbricação entre o pensamento utópico hodierno e o Direito reflete as novas relaçóes sociais que emergem neste processo histórico-espacial que marca o início da secunda década deste novo século. Neste cenário é possível vislumbrar a transformação do próprio ordenamento jurídico, em uma correlação de forças que implique no avanço das lutas empreendidas pelos novos atores sociais protagonistas das manifestaçóes que traduzem as atuais açóes emancipatórias.

Esta Nova Utopia, diferente do utopismo tradicional (das formas espaciais) e do utopismo dos processos sociais, se aproxima do conceito de Utopia Dialética formulada por David Harvey. Este artigo não tem a pretensão de buscar a sistematizaçáo do projeto utópico em curso, pois sua constituição encontra-se em pleno andamento. No entanto, ao situar a rua como território onde se desenvolve a formulação e concretização desta Nova Utopia o que se pretende destacar é a centralidade das práticas cotidianas de homens e mulheres comuns e que buscam se construir como atores de sua própria emancipação. $\mathrm{E}$ neste processo a luta pelo Direito, em especial o Direito à Cidade, assume um papel de destaque.

\section{Síntese}

O utopismo tradicional pode ser defino como toda proposta ideal de organização da sociedade que, por meio de novas condiçóes econômicas, políticas e sociais, se pretende alcançar um estado de satisfação geral. Por sua vez o utopismo do processo temporal não busca definir o projeto utópico em si, mas a forma que ele se pode conquistar a mesma satisfação geral da sociedade.

As Novas Utopias que florecem neste momento histórico, onde os projetos de sociedade em disputa durante o século passado, o capitalismo e o socialismo, passam por uma profunda crise, se aproxima do conceito de utopismo dialético. Onde o projeto utópico é construído concomitante às práticas emancipatórias que se desenvolvem em um território específico, ou seja as ruas e demais espaços comuns existentes nas áreas urbanas. É neste território que o embate entre o projeto rebelbe a ser construído e as forças conservadores será travado até o final.

\section{Referências}

ARENDT, H. A condição humana. Rio de Janeiro: Forense Universitário, 2003.

CAMPNELLA, T. A cidade do sol. São Paulo: Martin Claret, 2004.

HARVEY, D. Espaços de esperança. São Paulo: Edições Loyola, 2009.

HERKENHOFF, J. B. Direito e utopia. Porto Alegre: Livraria do Advogado, 2004. 
LEFEBVRE, H. A revoluçáo urbana. Belo Horizonte: Umanitas, 2008. . Direito à cidade. São Paulo: Centauro, 2008.

MANNHEIN, K. Ideologia e utopia. Rio de Janeiro: Zahar, 1972.

MARX, K. ENGELS, F. Manifesto do Partido Comunista. São Paulo: Novos Rumos, 1986.

MORE, T. A Utopia. São Paulo: Martin Claret, 2005.

PASUKANIS, E. B. A teoria do direito e o marximo. Rio de Janeiro: Renovar, 1989.

PLATÃO. A República. São Paulo: Martin Claret, 2002.

SOUZA, M. L. A prisão e a ágora: reflexões em torno da democratização do planejamento e da gestão das cidades. Rio de Janeiro: Bertrand Brasil, 2006.

STEFANIAK, J. L. Entre a miragem e a utopia: a efetividade do direito humano e fundamental à moradia na cidade capitalista. Dissertação (Mestrado em Ciências Sociais Aplicadas). Ponta Grossa: UEPG, 2011. 